\title{
Crystalline bacterial biofilm formation on urinary catheters by urease-producing urinary tract pathogens: a simple method of control
}

\section{Correspondence \\ David J. Stickler \\ stickler@cardiff.ac.uk}

Received 29 April 2009

Accepted 19 June 2009

\author{
Robert J. Broomfield, ${ }^{1}$ Sheridan D. Morgan, ${ }^{1}$ Azhar Khan ${ }^{2}$ \\ and David J. Stickler ${ }^{1}$ \\ ${ }^{1}$ Cardiff School of Biosciences, Cardiff University, Cardiff CF10 3TL, UK \\ ${ }^{2}$ BioMed Centre, Bristol Urological Institute, Southmead Hospital, Bristol, UK
}

\section{INTRODUCTION}

A common complication in the care of patients undergoing long-term indwelling bladder catheterization is encrustation and blockage of the catheter (Stickler \& Zimakoff, 1994). It can result in emergency referrals of patients in acute discomfort with urinary retention or incontinent of urine because of sudden catheter blockage (Kohler-Ockmore \& Feneley, 1996). The problem stems from infection by urease-producing bacteria that colonize the catheter forming extensive biofilms. The bacterial urease generates ammonia from urea, elevating the $\mathrm{pH}$ of urine and biofilm. As the $\mathrm{pH}$ of urine rises, crystals of calcium and magnesium phosphates come out of solution. The $\mathrm{pH}$ at which this occurs is known as the nucleation $\mathrm{pH}$ $\left(\mathrm{pH}_{\mathrm{n}}\right)$ (Choong et al., 2001). In patients who develop infections with urease-producing bacteria, the $\mathrm{pH}$ of the voided urine $\left(\mathrm{pH}_{\mathrm{v}}\right)$ can thus rise above the $\mathrm{pH}_{\mathrm{n}}$ and crystallization occurs in the urine and the biofilm. The continued development of this crystalline biofilm blocks the flow of urine through the catheter (Morris et al., 1999).

Abbreviations: $\mathrm{pH}_{\mathrm{n}}$, nucleation $\mathrm{pH} ; \mathrm{pH}_{\mathrm{v}}, \mathrm{pH}$ of the voided urine.
All available types of indwelling catheters are vulnerable to this problem (Morris et al., 1997) and currently there are no effective procedures available for its control (Kunin, 1997).

There is strong epidemiological and experimental evidence that Proteus mirabilis is a major cause of catheter encrustation (Mobley \& Warren, 1987; Kunin, 1989; Stickler et al., 1993). A strategy has been developed to prevent crystalline biofilm formation by this organism. It simply involves diluting urine and increasing its citrate concentration. This elevates the $\mathrm{pH}_{\mathrm{n}}$ of urine above the $\mathrm{pH}$ which $P$. mirabilis normally generates in urine (Stickler \& Morgan, 2006). A wide range of organisms will colonize the urine and catheters of patients undergoing long-term catheterization (MacLeod \& Stickler, 2007) and several are capable of producing urease in standard bacteriological identification tests. A preliminary study in laboratory models by Stickler et al. (1998) found that of these other species, Proteus vulgaris and Providencia rettgeri were capable of generating alkaline urine and producing crystalline biofilms over $24 \mathrm{~h}$ incubation periods. The aims of the present study were to (a) test the ability of these 
organisms and an extended range of urease-producing species to block catheters; (b) examine the effect of the citrate strategy on catheter encrustation by crystalline biofilm-forming species; and (c) test whether by increasing fluid intake of a healthy volunteer with citrated drinks it was possible to raise the $\mathrm{pH}_{\mathrm{n}}$ of urine above the $\mathrm{pH}_{\mathrm{v}}$ generated by urease-positive species, thus producing urine in which catheter encrustation is inhibited.

\section{METHODS}

Bacterial strains and culture media. The organisms used in this study were isolated from the biofilms colonizing catheters of patients undergoing long-term bladder catheterization (MacLeod \& Stickler, 2007). They had all been screened for urease activity on urea agar slopes. The artificial urine used in the experimental work was based on that devised by Griffith et al. (1976). It contained calcium chloride $0.49 \mathrm{~g}$ $\mathrm{l}^{-1}$, magnesium chloride hexahydrate $0.65 \mathrm{~g} \mathrm{l}^{-1}$, sodium chloride $4.6 \mathrm{~g}$ $\mathrm{l}^{-1}$, di-sodium sulphate $2.3 \mathrm{~g} \mathrm{l}^{-1}$, tri-sodium citrate dihydrate $0.65 \mathrm{~g}$ $1^{-1}$, di-sodium oxalate $0.02 \mathrm{~g} \mathrm{l}^{-1}$, potassium dihydrogen phosphate $2.8 \mathrm{~g} \mathrm{l}^{-1}$, potassium chloride $1.6 \mathrm{~g} \mathrm{l}^{-1}$, ammonium chloride $1.0 \mathrm{~g} \mathrm{l}^{-1}$, urea $25 \mathrm{~g} \mathrm{l}^{-1}$, gelatin $5.0 \mathrm{~g} \mathrm{l}^{-1}$. The $\mathrm{pH}$ of the medium was adjusted to 6.1 and then the medium was sterilized by membrane filtration. Tryptone soya broth (Oxoid) was prepared separately, autoclaved and added to the sterile basal medium to a final concentration of $1.0 \mathrm{~g} \mathrm{l}^{-1}$. When citrate was added, the urines were adjusted to this $\mathrm{pH}$ 6.1. CLED agar (Oxoid) was used for the enumeration of viable cells in urine.

The bladder model. The bladder model has been described previously (Stickler et al., 1999). In essence, it consists of a glass chamber maintained at $37{ }^{\circ} \mathrm{C}$ by a water jacket. Each model was sterilized by autoclaving and then a size $14 \mathrm{Ch}$ all-silicone catheter (Bard) was inserted into the chamber through an outlet at the base. The catheter retention balloons were inflated with $10 \mathrm{ml}$ sterile water and the catheters were connected to drainage bags in the normal way. Sterile artificial urine was pumped into the chambers so that residual volumes collected below the catheter eye-holes before flowing through the drainage tube to the collecting bags.

Experimental protocol. Sets of models were assembled and supplied with artificial urine up to the level of the catheter eye-holes. The urine supply was then switched off and $10 \mathrm{ml}$ of the artificial urine was removed from the bladder chamber and replaced with a $4 \mathrm{~h}$ artificial urine culture $(10 \mathrm{ml})$ of the various test organisms. These cultures were left for an hour to establish themselves in the bladder, and then the urine supply was resumed until catheter blockage. The times taken for the catheters to block were recorded. The urinary $\mathrm{pH}$ and the numbers of viable cells in the urine voided from the model were measured at intervals up to 7 days or the time of catheter blockage.

Scanning electron microscopy of catheter sections. Catheters were removed from the models and sections ( $1 \mathrm{~cm}$ in length) were cut from the region above the retention balloon. In some cases, these sections were examined directly at low power using the low vacuum facility of a JEOL 5200 scanning electron microscope. Other sections were perfusion-fixed in $2.5 \%$ glutaraldehyde in $0.1 \mathrm{M}$ Sörensen buffer ( $\mathrm{pH} 8)$ ( $4 \mathrm{~h}$ at room temperature or overnight at $4{ }^{\circ} \mathrm{C}$ ). Subsequently catheter sections were washed in the buffer for $15 \mathrm{~min}$ before post-fixing using a 1:1 solution of $0.05 \mathrm{M}$ buffer, $1 \%$ osmium tetroxide for $1 \mathrm{~h}$. A further $15 \mathrm{~min}$ wash in distilled water was carried out before samples were dehydrated in an ascending ethanol series. Sections were then dried by sublimation dehydration using hexamethyldisilizane (HMDS), i.e. $70 \%, 90 \%, 100 \%, 100 \%$ ethanol, $100 \%$ ethanol:HMDS $(1: 1)$. Finally, they were washed twice in
$100 \%$ HMDS (15 min each step) and left to dry in air. In some cases, sections were dried using a critical point drier (Blazers CPD 030, BalTec Ag). The samples were gold sputter-coated (Edwards S150P sputter-coater) and visualized using a Philips XL-20 scanning electron microscope, accelerating voltage $20-25 \mathrm{kv}$.

Urease assay. Test organisms were grown for $4 \mathrm{~h}$ at $37{ }^{\circ} \mathrm{C}$ with aeration in artificial urine. The cells were harvested by centrifugation and then resuspended in $0.1 \mathrm{M}$ sodium phosphate buffer ( $\mathrm{pH} 7.3$ ) containing $10 \mathrm{mM}$ EDTA. The assay based on the modified Bertholt reaction (Creno et al., 1970) was used to determine the urease activity of the whole-cell suspension. Cell suspensions $(200 \mu \mathrm{l})$ were added to a reaction mixture containing $50 \mathrm{mM}$ urea and $100 \mathrm{mM}$ sodium phosphate buffer ( $\mathrm{pH} 7.3$ ) and incubated at $37^{\circ} \mathrm{C}$ for $10 \mathrm{~min}$. The reaction was terminated by the addition of $2 \mathrm{ml}$ of a solution of phenol $(0.5 \%)$ and sodium nitroprusside $(0.0025 \%)$. Subsequently $2 \mathrm{ml}$ of a solution of sodium hydroxide and sodium hypochlorite $(0.21 \%)$ was added and colour development was allowed to proceed for $6 \mathrm{~min}$ at $56{ }^{\circ} \mathrm{C}$. The $\mathrm{OD}_{600}$ was measured against a reagent blank and the amount of ammonia and therefore the amount of urea hydrolysed were calculated from standard curves prepared using solutions of ammonium chloride. Protein levels in the cell suspensions were determined using commercial protein determination kits (Sigma). The urease activity was then expressed as $\mu$ mol urea hydrolysed $\min ^{-1}$ (mg protein $)^{-1}$.

Determination of the $\mathbf{p H}_{\mathbf{n}}$ of urine. Evaluation of $\mathrm{pH}_{\mathbf{n}}$ was based on the method described by Choong et al. (1999). Urine was maintained at $37{ }^{\circ} \mathrm{C}$, and samples were alkalinized in increments of $0.20 \mathrm{pH}$ units with $1 \mathrm{M}$ sodium hydroxide solution up to a $\mathrm{pH}$ of 10 . At each increment, the $\mathrm{OD}_{600}$ was measured against urine at $\mathrm{pH} 5.0$ as a blank with a Unicam Helios $\gamma$ spectrophotometer. The $\mathrm{pH}_{\mathrm{n}}$ was determined from the resulting plot of $\mathrm{pH}$ versus optical density. The $\mathrm{pH}_{\mathrm{n}}$ was defined by an abrupt change in the slope of the graph showing an increase in turbidity. Plotting $\mathrm{pH}$ versus optical density produces two straight-line segments which intersect at the $\mathrm{pH}_{\mathrm{n}}$. Regression lines were calculated by least-squares analysis for these two portions of the graph and used to determine the $\mathrm{pH}$ at their intersection.

Determination of the rate of calcium and magnesium deposition on catheters. At the end of each experimental period, catheters were removed from the models, the inflation balloons were dissected away from the catheters and the whole length of the catheter was cut into $1 \mathrm{~cm}$ sections. These sections were placed into $100 \mathrm{ml} 4 \%(\mathrm{v} / \mathrm{v})$ nitric acid in double deionized water and sonicated at $35 \mathrm{kHz}$ for $5 \mathrm{~min}$ in the Transsonic water bath to aid biofilm removal and disruption. Samples were stood for at least $48 \mathrm{~h}$ to allow the crystals to dissolve. The calcium and magnesium content of the resulting solutions was then assayed using flame atomic absorption spectroscopy in a SpectrAA-100 spectrophotometer (Varian) calibrated with Spectrosol standards obtained from VWR International. Samples were aspirated into the flame (air-acetylene for magnesium and nitrous oxideacetylene for calcium). Calcium was measured at $422.7 \mathrm{~nm}$ and magnesium at $285.2 \mathrm{~nm}$. The rate of catheter encrustation was then expressed as $\mu \mathrm{g} \mathrm{Ca}$ and $\mathrm{Mg}$ deposited per catheter $\mathrm{h}^{-1}$.

Statistical analysis. One-way ANOVA carried out at a $95 \%$ confidence interval was the statistical test of choice for all the experiments. This was carried out using Minitab release 13 software. Where appropriate, the standard error (SE) of the mean is indicated.

\section{RESULTS AND DISCUSSION}

The ability of urease-positive isolates of 11 species of urinary tract pathogens to block catheters in the bladder 
model was examined over $96 \mathrm{~h}$ test periods in which the basic artificial urine was supplied to the models at $0.5 \mathrm{ml} \mathrm{min}{ }^{-1}$. Urease-negative isolates of Escherichia coli and Staphylococcus aureus were also included in the study for comparison. The results from triplicate experiments are presented in Table 1. In the case of the control ureasenegative organisms, the urinary $\mathrm{pH}$ remained acid at around 6.1. All the urease-positive species raised the $\mathrm{pH}$ of urine significantly $(P<0.05)$ in the model over the incubation period. The isolates fell into three distinct groups. Klebsiella pneumoniae, Klebsiella oxytoca, Enterobacter cloacae, Serratia marcescens, Pseudomonas aeruginosa and Providencia stuartii generated urinary $\mathrm{pHs}$ of 6.2-6.4. Staph. aureus and Morganella morganii produced urinary $\mathrm{pHs}$ of 6.9-7.4. P. mirabilis, P. vulgaris and $P v$. rettgeri generated considerably more alkaline urine ( $\mathrm{pH}$ 8.3-8.4) and caused the rapid blockage of the catheters. None of the other isolates produced blockage over the $96 \mathrm{~h}$. Photographs of catheters taken from the models at blockage or $96 \mathrm{~h}$ (Fig. 1) show the extent of encrustation around the catheter eye-holes and central channels.

The $\mathrm{pH}_{\mathrm{n}}$ of the urine supplied to the models was 6.7, explaining why there were no signs of crystal deposition on catheters colonized by the urease-negative organisms and by those urease-positive species only capable of elevating the urinary $\mathrm{pH}$ to 6.2-6.4 (Fig. 2). As the Staph. aureus and M. morganii isolates elevated the $\mathrm{pH}$ above the $\mathrm{pH}_{\mathrm{n}}$, a degree of crystallization was found in their biofilms at $96 \mathrm{~h}$ (Fig. 3c, d). Encrustation was obviously less extensive, however, than in the cases of those species capable of

Table 1. Times catheters took to block and urinary $\mathrm{pH}$ values in models inoculated with a range of urease-producing isolates

\begin{tabular}{|lcc|}
\hline Organism & $\begin{array}{c}\text { Time }(\mathbf{h}) \text { to } \\
\text { catheter } \\
\text { blockage }( \pm \mathrm{SE})^{*}\end{array}$ & $\begin{array}{c}\text { pH of urine at } \\
\text { blockage or } \\
\mathbf{9 6} \mathbf{~ h}( \pm \mathrm{SE})\end{array}$ \\
\hline Proteus mirabilis RB6 & $19.8(2.9)$ & $8.34(0.19)$ \\
Proteus vulgaris SDM2 & $36.4(3.9)$ & $8.42(0.21)$ \\
Providencia rettgeri SDM1 & $32.2(6.2)$ & $8.36(0.19)$ \\
Morganella morganii RB15 & - & $7.39(0.08)$ \\
Staphylococcus aureus P10 6/9 & - & $6.89(0.06)$ \\
Providencia stuartii RB14 & - & $6.44(0.06)$ \\
Pseudomonas aeruginosa RB16 & - & $6.32(0.05)$ \\
Klebsiella pneumoniae SDM17 & - & $6.31(0.05)$ \\
Serratia marcescens $\dagger$ & - & $6.18(0.01)$ \\
Klebsiella oxytoca $\dagger$ & - & $6.24(0.01)$ \\
Enterobacter cloacae $\dagger$ & - & $6.20(0.02)$ \\
Staphylococcus aureus W112 & - & $6.09(0.01)$ \\
urease - ve & - & $6.15(0.02)$ \\
Escherichia coli RB13 urease $-\mathrm{ve}$ & - & $6.11(0.01)$ \\
Uninoculated control & & \\
\end{tabular}

${ }^{*}$-, Indicates that the catheters did not block in the $96 \mathrm{~h}$ test period. $\dagger$ In these cases, the mean values were calculated from those obtained from single experiments with two to three different isolates. producing urinary $\mathrm{pH}$ values above 8.3 and blocking the catheters within $36 \mathrm{~h}$ (Fig. 3a, b).

Although $K$. pneumoniae did not generate crystalline biofilm, it did produce mucoid plugs in parts of the catheter lumen (Fig. 1). Similar plugs were produced by Ps. aeruginosa (not shown). While these did not completely block the catheters, they did restrict the flow of urine. Poorly draining catheters in patients are occasionally obstructed by mucus. Examination of this material might reveal it to be mucoid bacterial biofilm.

The amounts of calcium and magnesium deposited on catheters removed from the models at blockage or $96 \mathrm{~h}$ were determined by flame atomic absorption spectroscopy. The overall rates of encrustation were calculated and the results are presented in Table 2. The three species that blocked catheters clearly produced the most rapid encrustation. Of the other organisms, only $M$. morganii produced appreciable rates above baseline. The urease activity of $4 \mathrm{~h}$ urine cultures of the test organisms is also presented in Table 2. These results show that while species such as K. pneumoniae, Ps. aeruginosa, Pv. stuartii and Staph. aureus can produce urease on urea agar in standard bacteriological identification tests, the activity that they produce in urine is substantially less than that produced by P. mirabilis, P. vulgaris, Pv. rettgeri and M. morganii.

Antimicrobial catheters (the silver/hydrogel-coated latex Bard IC catheter and the nitrofurazone-impregnated allsilicone catheter, Rochester Medical NF catheter) have been introduced recently into clinical practice. It has been shown that $P$. mirabilis is capable of encrusting and blocking these antimicrobial catheters in vitro and in vivo (Stickler \& Morgan, 2008; Morgan et al., 2009). Experiments were performed in the bladder models to test the abilities of the other species that were capable of forming crystalline biofilm in urine to encrust and block these catheters. All-silicone catheters were used as controls. The models were run until catheters blocked or for a total of $168 \mathrm{~h}$. The results presented in Table 3 show the rapid blockage of the silicone and the silver and nitrofurazone catheters by $P$. mirabilis, $P$. vulgaris and $P v$. rettgeri. Staph. aureus failed to block any of the catheters during the incubation period. The results show that given the longer incubation period of $168 \mathrm{~h}, \mathrm{M}$. morganii was capable of blocking all-silicone and NF catheters. The silver catheter, however, did not block. It is clear from the images presented in Fig. 4, however, that while there was little sign of crystalline biofilm formed by Staph. aureus on the antimicrobial catheters, the other four species all produced extensive encrustation on both these catheters, and $M$. morganii must have been very close to blocking the silver catheters at $168 \mathrm{~h}$.

Previous studies have shown that $P$. mirabilis is very sensitive to the biocide triclosan (Stickler, 2002). A strategy to control crystalline biofilm formation by this organism was thus developed which involved inflating the catheter retention balloon with triclosan solution rather than water. 


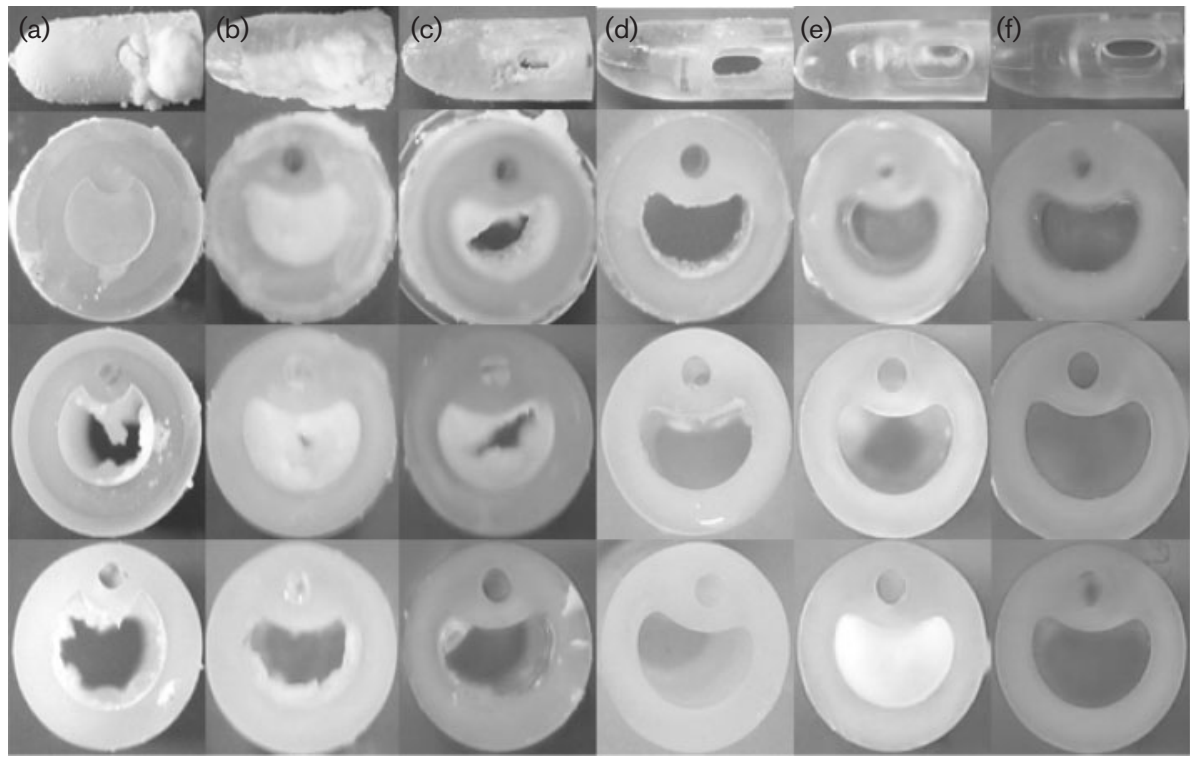

Fig. 1. Each column shows the eye-holes and a series of cross-sections taken along the length of catheters removed from models that had been inoculated with (a) P. vulgaris SDM2, (b) Pv. rettgeri SDM1, (c) M. morganii RB15, (d) Staph. aureus P10 $6 / 9$, (e) K. pneumoniae SDM1 7 and (f) E. coli RB13. The catheters in (a) and (b) were removed from models at blockage; those in (c)-(f) were removed after 4 days incubation. E. coli was included as a urease-negative organism; all other organisms shown were urease producers.
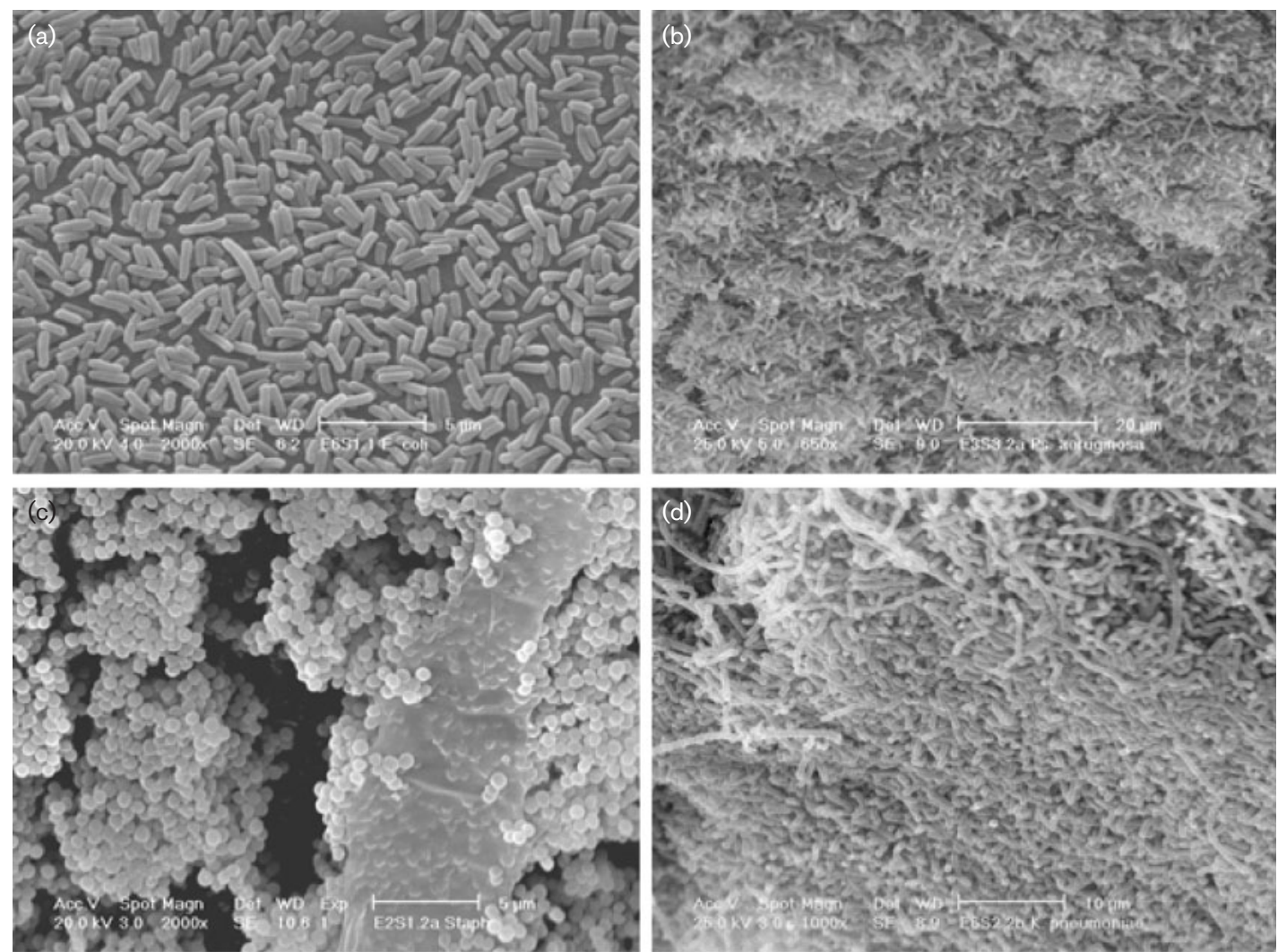

Fig. 2. Scanning electron micrographs of biofilms growing on catheters removed from models after 4 days incubation. (a) Urease-negative E. coli RB13; (b) urease-positive Ps. aeruginosa RB16; (c) urease-negative Staph. aureus (W112); and (d) urease-positive K. pneumoniae SDM17. 


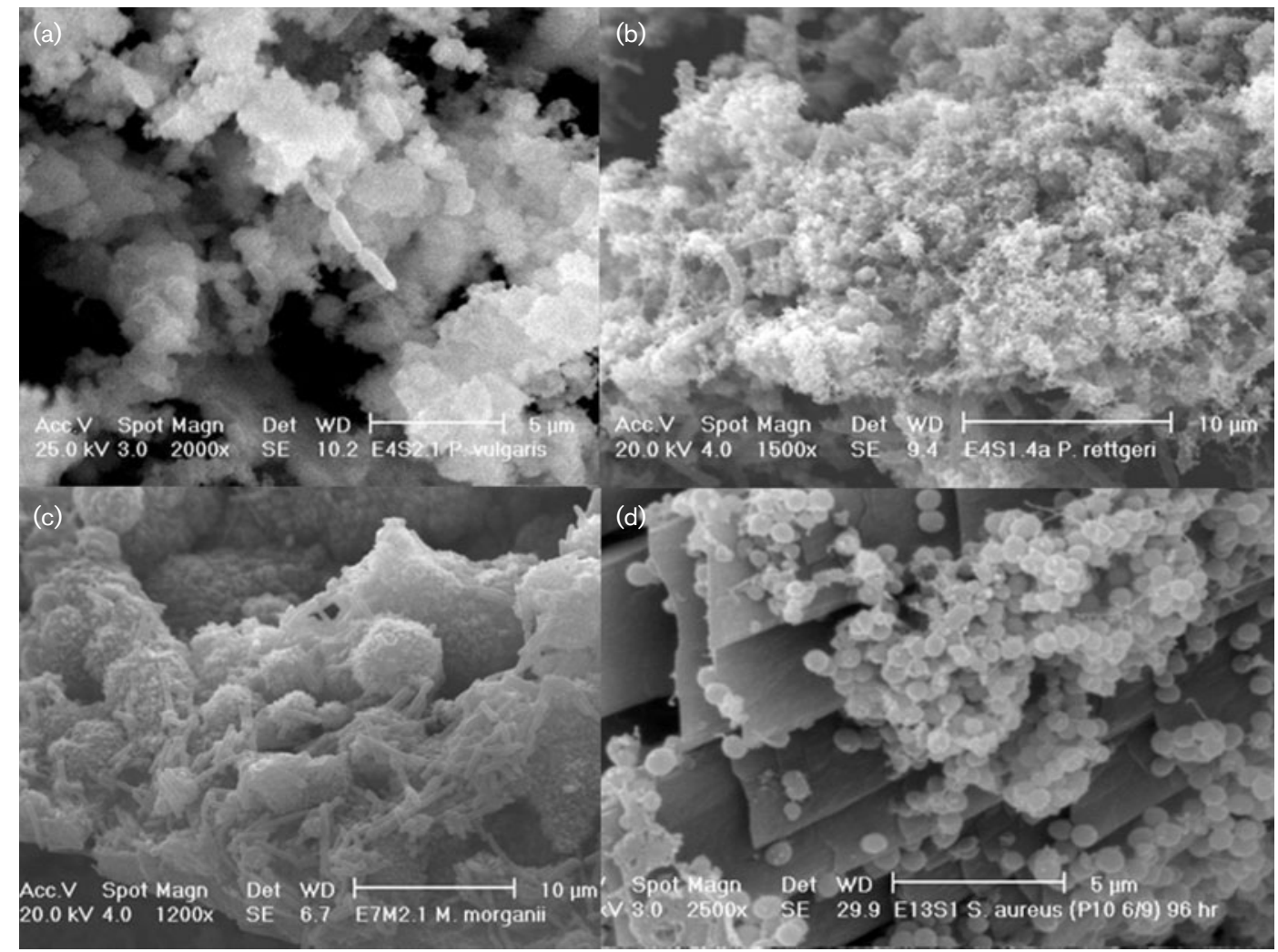

Fig. 3. Scanning electron micrographs of crystalline biofilms. (a) P. vulgaris SDM2 biofilm at catheter blockage; (b) Pv. rettgeri SDM1 biofilm at catheter blockage; (c) M. morganii RB15 biofilm on a catheter that was still draining after 96 h; and (d) ureasepositive Staph. aureus P10 6/9 biofilm on a catheter removed from a model after $96 \mathrm{~h}$.

The biocide was shown to diffuse slowly through the balloon membrane, reducing the urinary bacterial populations, preventing the rise in urinary $\mathrm{pH}$ and inhibiting catheter encrustation (Stickler et al., 2003). In view of these results, the susceptibilities of isolates of $P$. vulgaris and $P v$. rettgeri from catheter-associated urinary tract infections to triclosan were tested. The results presented in Table 4 show that whereas $P$. vulgaris is fully sensitive to the biocide (MICs $0.05-0.1 \mu \mathrm{g} \mathrm{ml}^{-1}$ ), Pv. rettgeri is resistant to the concentrations achievable in urine (MIC $64 \mu \mathrm{g} \mathrm{ml}{ }^{-1}$ ).

Table 2. Rate of catheter encrustation and urease activity of a range of urinary pathogens growing in artificial urine for $4 \mathrm{~h}$ in shake flask culture

Mean values calculated from three replicate experiments. Isolates of Klebsiella oxytoca, Serratia marcescens and Enterobacter cloacae produced urease activity of $<0.1$ units $\mathrm{ml}^{-1}$.

\begin{tabular}{|c|c|c|}
\hline Organism & $\begin{array}{c}\text { Rate of encrustation of } \\
\mathrm{Ca}+\mathrm{Mg}\left(\boldsymbol{\mu g} \text { per catheter } \mathrm{h}^{-1}\right)\end{array}$ & $\begin{array}{c}\text { Urease activity [ } \mu \mathrm{mol} \text { urea } \\
\text { hydrolysed } \min ^{-1}(\mathrm{mg} \text { protein })^{-1} \text { ] }\end{array}$ \\
\hline Proteus mirabilis RB6 & $260.0(9.36)$ & $2.34(0.21)$ \\
\hline Proteus vulgaris SDM2 & $193.1(27.25)$ & $2.13(0.19)$ \\
\hline Providencia rettgeri $\mathrm{SDM} 1$ & $178.9(51.13)$ & $1.85(0.22)$ \\
\hline Morganella morganii $\mathrm{RB} 15$ & $56.5(15.96)$ & $1.34(0.09)$ \\
\hline Staphylococcus aureus P10 6/9 & $11.2(3.63)$ & $0.28(0.05)$ \\
\hline Providencia stuartii RB14 & $13.9(4.12)$ & $0.10(0.02)$ \\
\hline Pseudomonas aeruginosa RB16 & $16.3(6.19)$ & $0.06(0.01)$ \\
\hline Klebsiella pneumoniae SDM17 & $7.2(1.41)$ & $0.07(0.02)$ \\
\hline Escherichia coli RB13 urease - ve & $7.7(1.44)$ & $0.06(0.02)$ \\
\hline
\end{tabular}


Table 3. Times taken for five urease-positive species to block silver, nitrofurazone and all-silicone catheters

Mean values calculated from three replicate experiments.

\begin{tabular}{|lccc|}
\hline \multirow{2}{*}{ Organism } & \multicolumn{2}{c|}{ Mean blockage times $(\mathbf{h})( \pm \mathrm{SE})$ for each type of catheter } \\
\cline { 2 - 4 } & All-silicone & Silver/latex & Nitrofurazone \\
\hline Proteus mirabilis RB6 & $20.0(2.6)$ & $15.7(2.0)$ & $26.7(3.2)$ \\
Proteus vulgaris SDM2 & $25.0(2.0)$ & $23.7(1.3)$ & $27.0(2.5)$ \\
Providencia rettgeri SDM1 & $26.7(7.9)$ & $15.3(0.9)$ & $29.7(6.1)$ \\
Morganella morganii RB15 & $149(13.0)$ & $>168$ & $>131.3(12.2)$ \\
Staphylococcus aureus P10 6/9 & $>168$ & $>168$ & $>168$ \\
\hline
\end{tabular}

Subsequent testing in bladder models in which retention balloons were inflated with triclosan $\left(3 \mathrm{mg} \mathrm{ml}^{-1}\right)$ revealed that while the biocide prevented catheter blockage by $P$. mirabilis and $P$. vulgaris, it had little effect on catheter encrustation by $P v$. rettgeri (Table 4 ).

A previous study had shown that isolates of $M$. morganii from patients' catheters were also resistant to triclosan (MIC $>100 \mu \mathrm{g} \mathrm{ml}^{-1}$ ) and that this species could form catheter biofilms in the presence of triclosan (Jones et al., 2006). As $P$. mirabilis is currently the main cause of the problem, however, the results suggest that the triclosan strategy should prevent catheter encrustation in most cases. As with any intervention with an antibacterial agent, there is the danger that the strategy will select for resistant species, e.g. $P v$. rettgeri and M. morganii, or even possibly generate triclosan resistance in $P$. mirabilis (Stickler \& Jones, 2008).

The prospective study of Mathur et al. (2005) of catheterized patients infected with $P$. mirabilis found that there was a significant $(P=0.004)$ positive correlation between the mean $\mathrm{pH}_{\mathrm{n}}$ of their urine and catheter lifespan. The higher the urinary $\mathrm{pH}_{\mathrm{n}}$ and the larger the safety margin between $\mathrm{pH}_{\mathrm{n}}$ and $\mathrm{pH}_{\mathrm{v}}$, the slower the rate of encrustation and the longer catheters took to block. It was also shown that the $\mathrm{pH}_{\mathrm{n}}$ of the urine of these patients varied between individuals and from week to week in any one individual. It was suggested that if $\mathrm{pH}_{n}$ can be manipulated in order to increase the safety margin between $\mathrm{pH}_{\mathrm{v}}$ and $\mathrm{pH}_{\mathrm{n}}$, a strategy for controlling catheter encrustation could be devised which does not involve intervention by antibacterial agents.

Suller et al. (2005) in a study of urine from healthy volunteers found that simply by increasing fluid and citrate intakes, the $\mathrm{pH}_{\mathrm{n}}$ of urine could be elevated to values that are rarely achieved even in $P$. mirabilis-infected urine. Subsequent experiments (Stickler \& Morgan, 2006) in a laboratory model infected with $P$. mirabilis confirmed that when models were supplied with an artificial dilute citratecontaining urine with a $\mathrm{pH}_{\mathrm{n}}>8.3$, crystalline biofilms did not form. The effect of manipulating urinary $\mathrm{pH}_{\mathrm{n}}$ on the ability of $P$. vulgaris and $P v$. rettgeri to encrust and block catheters was therefore examined. Artificial urine at half the basic strength, containing $0.205 \mathrm{~g} \mathrm{l}^{-1}$ and $1.5 \mathrm{~g} \mathrm{l}^{-1}$ citrate $\left(\mathrm{pH}_{\mathrm{n}}\right.$ of 6.9 and 8.3 , respectively), was supplied to models at $1 \mathrm{ml} \mathrm{min}^{-1}$. Models were inoculated with the test organisms and incubated for 7-day experimental
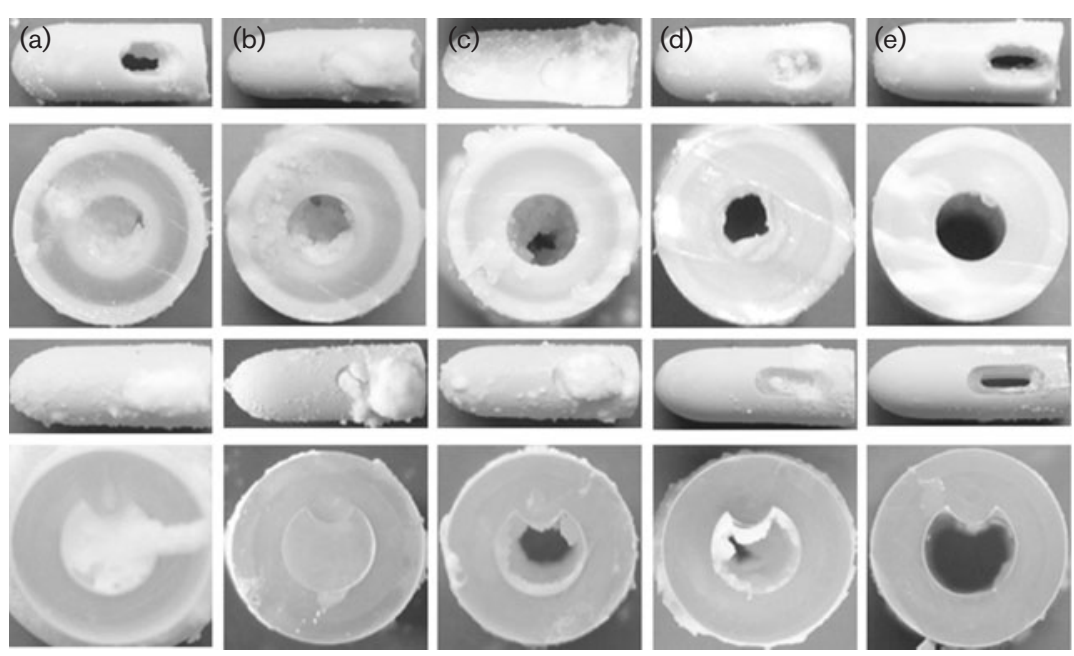

Fig. 4. Columns show the eye-holes and luminal cross-sections of antimicrobial catheters removed from models that had been inoculated with (a) $P$. mirabilis RB6, (b) $P$. vulgaris SDM2, (c) Pv. rettgeri SDM1, (d) $M$. morganii RB15 and (e) Staph. aureus P10 6/9. The catheters in (a), (b) and (c) were removed from models at blockage; those in (d) and (e) were removed after $168 \mathrm{~h}$ incubation. The top two rows are of silver/latex catheters; the bottom two rows show nitrofurazone/silicone catheters. 
Table 4. Effect of inflating catheter balloons with triclosan ( $3 \mathrm{mg} \mathrm{m}^{-1}$ in $0.1 \mathrm{M}$ sodium carbonate) on the times to catheter blockage

\begin{tabular}{|c|c|c|c|c|}
\hline \multirow[t]{2}{*}{ Organism } & \multirow[t]{2}{*}{ MIC of triclosan $\left(\mu \mathrm{g} \mathrm{ml}^{-1}\right)$} & \multicolumn{3}{|c|}{ Mean times $( \pm \mathrm{SE})\left(\right.$ h) to catheter blockage ${ }^{\star}$} \\
\hline & & Water control & $0.1 \mathrm{M} \mathrm{Na}_{2} \mathrm{CO}_{3}$ & Triclosan \\
\hline Proteus vulgaris SDM2 & 0.1 & $27.0(2.0)$ & $38.7(7.7)$ & $>168$ \\
\hline Providencia rettgeri SDM1 & 64 & $30.7(0.3)$ & $32.3(6.0)$ & $41.7(8.5)$ \\
\hline
\end{tabular}

${ }^{\star}$ Mean values calculated from three replicate experiments.

periods. The times taken for the catheters to block were recorded in four replicate experiments (Table 5). It is clear that with all three species, increasing the $\mathrm{pH}_{\mathrm{n}}$ of urine extends the lifespan of the catheters. Scanning electron micrographs of the catheters removed after $24 \mathrm{~h}$ from models that had been inoculated with Pv. rettgeri (Figs 5 and 6) confirm that at high urinary $\mathrm{pH}_{\mathrm{n}}$ values crystalline biofilm formation is inhibited. Similar observations were made on catheters from models inoculated with $P$. vulgaris.

The next step in the development of this strategy was to supply models with human urine from individuals who had high fluid and citrate intakes and observe the effects on catheter encrustation by $P$. mirabilis. A selection of fruit juices with high citrate contents were considered for use in the study. After tasting sessions, a drink containing a mixture of lemon and orange juice at a ratio of $1: 4$ was used. A total of $750 \mathrm{ml}$ of this drink was consumed by a healthy volunteer in $250 \mathrm{ml}$ aliquots at three evenly spaced intervals throughout the day. This achieved a dietary supplement of $11 \mathrm{~g}$ citrate. This is a modest increase in fluid intake compared to that suggested by Seltzer et al. (1996) as a treatment for kidney stones. These workers reported that the daily consumption of 21 of a lemonade drink reduced kidney stone formation. A similar regimen involving the daily consumption of a drink containing $140 \mathrm{ml}$ lemon juice and $250 \mathrm{ml}$ summer fruit drink to aid palatability, made up to 21 with tap water, was thus also selected for study.

The volunteer was subjected to four different fluid intake regimes each lasting a total of 3 days. In the first week, a

Table 5. Effect of urinary $\mathrm{pH}_{\mathrm{n}}$ on the blockage of catheters by $P$. mirabilis, $P$. vulgaris and $P v$. rettgeri

Means calculated from the results of four replicate experiments.

\begin{tabular}{|lcc|}
\hline \multirow{2}{*}{ Test organism } & \multicolumn{2}{c|}{ Mean times $(\mathbf{h})$ to blockage \pm SE } \\
\cline { 2 - 3 } & Urinary $\mathbf{p H}_{\mathbf{n}} \mathbf{6 . 9}$ & Urinary $\mathbf{p H}_{\mathbf{n}} \mathbf{8 . 3}$ \\
\hline Proteus mirabilis & $45.5 \pm 1.0$ & $>168$ \\
Proteus vulgaris & $47.4 \pm 2.2$ & $>168$ \\
Providencia rettgeri & $54.5 \pm 2.9$ & $>168$ \\
\hline
\end{tabular}

standardized fluid intake of $1300 \mathrm{ml}$ per $24 \mathrm{~h}$ (SFI) was consumed. In week 2 , this standard intake was supplemented with $750 \mathrm{ml}$ tap water $(\mathrm{SFI}+\mathrm{W})$. In week 3 , the fluid supplement was $750 \mathrm{ml}$ of the lemon/orange drink $(\mathrm{SFI}+\mathrm{C})$ and the final regime was SFI plus 21 of the lemon drink (SFI $+\mathrm{L})$. Urine voided was collected over $48 \mathrm{~h}$ on days 2 and 3. These dietary regimes were repeated over three independent periods. Intervals of 4 days were allowed between each regime. During the study, the volunteer was encouraged not to change any other aspect of diet or lifestyle. The volumes of urine collected during these periods were noted, and the $\mathrm{pH}_{\mathrm{v}}$ and $\mathrm{pH}_{\mathrm{n}}$ of pooled urine obtained from each regime were determined (Table 6). Urine was sterilized by filtration and then supplied to bladder models that were inoculated with $P$. mirabilis NSM6. The models were run until catheters blocked, the times to blockage being recorded (Table 6). The differences in the mean times to blockage of catheters in models supplied with urine collected during the SFI, SFI $+\mathrm{W}$ and $\mathrm{SFI}+\mathrm{C}$ regimes were not significantly different $(P>0.05)$. The mean lifespan of catheters in models supplied with

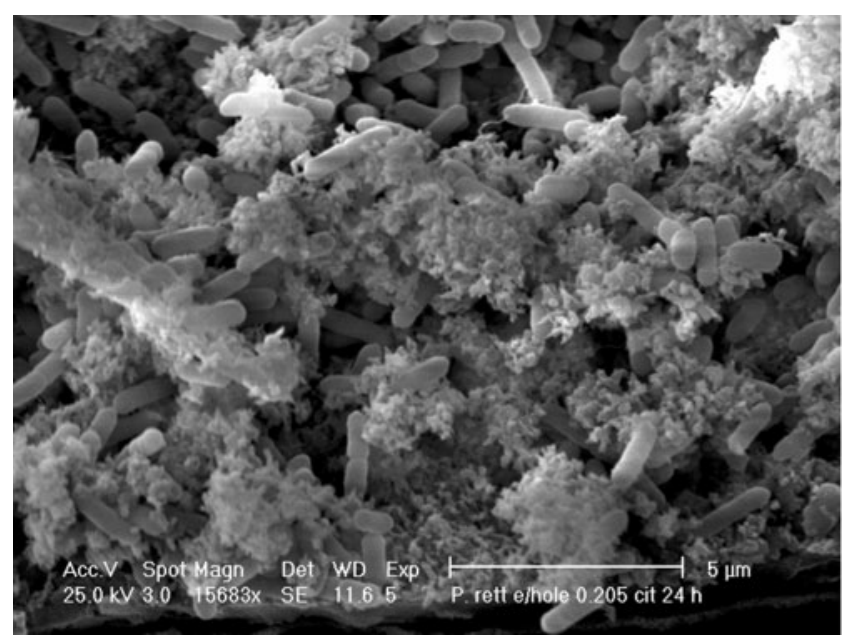

Fig. 5. Scanning electron micrograph of a $P v$. rettgeri SDM1 biofilm removed from a bladder model being supplied with urine having a $\mathrm{pH}_{\mathrm{n}}$ of 6.9 . Microcrystalline aggregates typical of apatite can be seen associated with the bacilli. 


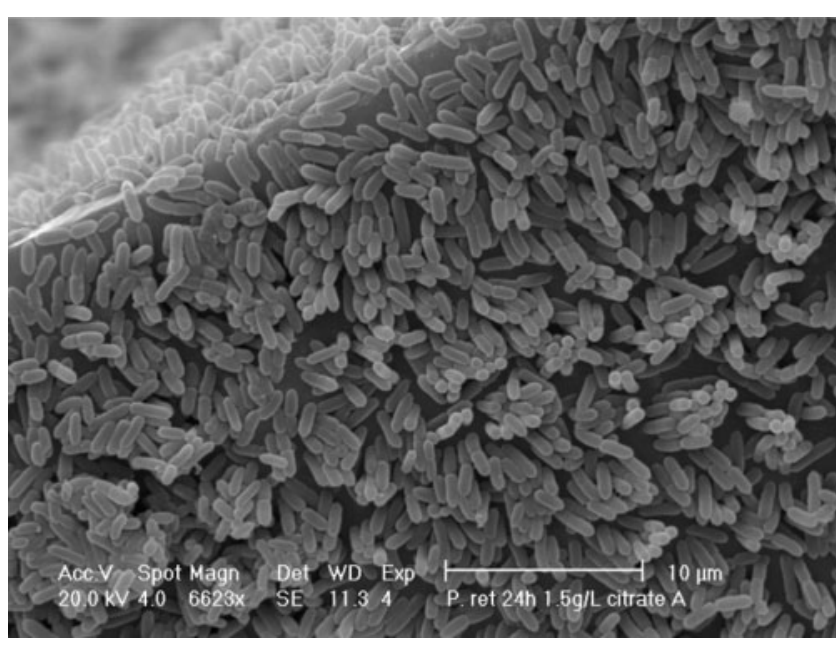

Fig. 6. Scanning electron micrograph of a $P v$. rettgeri SDM1 biofilm removed from a bladder model being supplied with urine having a $\mathrm{pH}_{\mathrm{n}}$ of 8.3 . It is clear that no crystalline material was deposited in the bacterial biofilm.

urine collected while the volunteer was on the lemonade dietary supplement was, however, significantly longer than those from models supplied with urine from the other three regimes $(P<0.05)$. Analysis of the data obtained for each of the 12 catheters used in this experiment showed a significant correlation between $\log \mathrm{pH}_{\mathrm{n}}$ and log time to blockage (Pearson's correlation coefficient $0.844, P<0.001$ ).

A study of the problem of catheter encrustation and blockage in spine-injured patients led Burr \& Nuseibeh (1997) to conclude that a high and uniform rate of fluid intake should be mandatory for a patient with a tendency to recurrent catheter blockage. Experimental evidence provided by Suller et al. (2005) and Stickler \& Morgan (2006) has also demonstrated that dilution of urine will elevate its $\mathrm{pH}_{\mathrm{n}}$ and slow the rate of catheter encrustation. Citrate is a natural chelating agent for divalent metal ions such as $\mathrm{Ca}^{2+}$ and $\mathrm{Mg}^{2+}$. In vitro studies have confirmed that increasing the citrate content of urine will inhibit the crystallization of calcium and magnesium phosphates (Wang et al., 1994), elevate the urinary $\mathrm{pH}_{\mathrm{n}}$ (Suller et al., 2005) and inhibit the encrustation of catheters by $P$. mirabilis (Stickler \& Morgan, 2006). The current data show that elevating the urinary $\mathrm{pH}_{\mathrm{n}}$ will inhibit catheter encrustation by the range of urease-positive species that are capable of producing extensive crystalline biofilms.

It is now necessary to establish the acceptability of the increased fluid regime to patients undergoing long-term catheterization and to determine whether it succeeds in elevating the safety margin between $\mathrm{pH}_{\mathrm{v}}$ and $\mathrm{pH}_{\mathrm{n}}$ and increasing the lifespan of catheters in patients prone to the encrustation problem. Another important issue is whether the strategy will be possible to implement and effective in the long term. Only experience will answer these questions. It is interesting, however, that Kang et al. (2007) reported no adverse effects in patients who had been consuming 21 of the lemonade drink daily for up to 8 years to control kidney stones.

In conclusion, it is clear that there is strong experimental evidence and a sound physiological and physical chemical basis for the conclusion that increasing patients' fluid intake with citrate-containing drinks will be an effective strategy for the control of catheter encrustation whichever bacterial species is causing the problem. A strategy which does not involve antibacterial agents and is effective against the spectrum of urease-positive organisms capable of causing the condition has the considerable advantage that the selection of resistant organisms will not be a problem. Bacteria have developed many ingenious ways of overcoming the challenge of antimicrobial agents but it is difficult to imagine that even they can do anything about the laws of physical chemistry that govern the solubility of calcium and magnesium phosphates in urine. A clinical trial is now required to examine the effect of this manipulation of patients' urinary $\mathrm{pH}_{\mathrm{n}}$ on catheter blockage, a complication that undermines the health and quality of life of so many elderly and disabled people.

Table 6. Characteristics of the human urine collected during the four fluid regimes

SFI, standard fluid intake; W, additional $750 \mathrm{ml}$ water per $24 \mathrm{~h}$; C, $750 \mathrm{ml}$ lemon/orange drink per $24 \mathrm{~h}$; L, 21 lemon drink per 24 h. The values quoted are means (SE) calculated from three replicate experiments.

\begin{tabular}{|c|c|c|c|c|}
\hline \multirow[t]{2}{*}{ Property } & \multicolumn{4}{|c|}{ Fluid intake regime } \\
\hline & SFI & $\mathrm{SFI}+\mathrm{W}$ & $\mathrm{SFI}+\mathrm{C}$ & $\mathrm{SFI}+\mathrm{L}$ \\
\hline Urine output $\mathrm{ml}$ per $48 \mathrm{~h}$ & $3633(90)$ & $4116(160)$ & $4833(320)$ & $7433(230)$ \\
\hline $\mathrm{pH}_{\mathrm{v}}$ & $5.91(0.26)$ & $6.1(0.21)$ & $6.77(0.05)$ & $6.29(0.35)$ \\
\hline $\mathrm{pH}_{\mathrm{n}}$ & $7.27(0.150$ & $7.7(0.09)$ & $7.86(0.19)$ & $8.1(0.17)$ \\
\hline $\mathrm{pH}_{\mathrm{n}}-\mathrm{pH}_{\mathrm{v}}$ & $1.36(0.09)$ & $1.61(0.22)$ & $1.1(0.19)$ & $1.81(0.17)$ \\
\hline Time (h) to catheter blockage & $25.2(5.1)$ & $35.6(2.3)$ & $44.0(8.1)$ & $118.1(20.1)$ \\
\hline
\end{tabular}




\section{ACKNOWLEDGEMENTS}

A.K. wishes to acknowledge support from the EU Framework VI Healthy Aims Programme.

\section{REFERENCES}

Burr, R. G. \& Nuseibeh, I. M. (1997). Urinary catheter blockage depends on urine $\mathrm{pH}$, calcium and rate of flow. Spinal Cord 35, 521525.

Choong, S. K. S., Hallson, P., Whitfield, H. N. \& Fry, C. H. (1999). The physicochemical basis of urinary catheter encrustation. BJU Int $\mathbf{8 3}$, 770-775.

Choong, S. K. S., Wood, S., Fry, C. H. \& Whitfield, H. N. (2001). Catheter associated urinary tract infection and encrustation. Int $J$ Antimicrob Agents 17, 305-310.

Creno, R. J., Wenk, R. E. \& Bohlig, P. (1970). Automated micromeasurement of urea using urease and the Berthelot reaction. Am J Clin Pathol 54, 828-832.

Griffith, D. P., Musher, D. M. \& Itin, C. (1976). Urease, the primary cause of infection-induced urinary stones. Invest Urol 13, 346-350.

Jones, G. L., Muller, C. T., O’Reilly, M. \& Stickler, D. J. (2006). Effect of triclosan on the development of bacterial biofilms by urinary tract pathogens on urinary catheters. J Antimicrob Chemother 57, 266-272.

Kang, D. E., Surl, R. L., Haleblian, G. E., Fitzsimons, N. J., Borawski, K. M. \& Preminger, G. M. (2007). Long-term lemonade-based dietary manipulation in patients with hypocitraturic nephrolithiasis. $J$ Urol 177, 1358-1362.

Kohler-Ockmore, J. \& Feneley, R. C. L. (1996). Long-term catheterization of the bladder: prevalence and morbidity. $\mathrm{Br} J$ Urol 77, 347-351.

Kunin, C. M. (1989). Blockage of urinary catheters: role of microorganisms and constituents of the urine on formation of encrustations. J Clin Epidemiol 42, 835-842.

Kunin, C. M. (1997). Urinary Tract Infections; Detection, Prevention and Management, 5th edn, pp. 226-278. Baltimore: Williams and Wilkins.

MacLeod, S. M. \& Stickler, D. J. (2007). Species interactions in mixedcommunity crystalline biofilms on urinary catheters. J Med Microbiol 56, 1549-1557.

Mathur, S., Suller, M. T. E., Stickler, D. J. \& Feneley, R. C. L. (2005). A prospective study of individuals with long-term urinary catheters colonized by Proteus sp. BJU Int 97, 121-128.

Mobley, H. L. T. \& Warren, J. W. (1987). Urease-positive bacteriuria and obstruction of long-term urinary catheters. J Clin Microbiol 25, 2216-2217.
Morgan, S. D., Rigby, D. \& Stickler, D. J. (2009). A study of the structure of the crystalline bacterial biofilms that can encrust and block silver Foley catheters. Urol Res 37, 89-93.

Morris, N. S., Winters, C. \& Stickler, D. J. (1997). Which indwelling urethral catheters resist encrustation by Proteus mirabilis biofilms? Br J Urol 80, 58-63.

Morris, N. S., Stickler, D. J. \& McLean, R. J. C. (1999). The development of bacterial biofilms on indwelling catheters. World $J$ Urol 17, 345-350.

Seltzer, M. A., Low, R. K., McDonald, M., Shami, G. S. \& Stoller, M. L. (1996). Dietary manipulation with lemonade to treat hypocitraturic calcium nephrolithiasis. J Urol 156, 907-909.

Stickler, D. J. (2002). Susceptibility of antibiotic-resistant Gramnegative bacteria to biocides: a perspective from a study of catheter biofilms. J Appl Microbiol 92, 163S-170S.

Stickler, D. J. \& Jones, G. L. (2008). Reduced susceptibility of Proteus mirabilis to triclosan. Antimicrob Agents Chemother 52, 991-994.

Stickler, D. J. \& Morgan, S. D. (2006). Modulation of crystalline Proteus mirabilis biofilm development on urinary catheters. J Med Microbiol 55, 489-494.

Stickler, D. J. \& Morgan, S. D. (2008). Observations on the development of the crystalline bacterial biofilms that encrust and block Foley catheters. J Hosp Infect 69, 350-360.

Stickler, D. J. \& Zimakoff, J. (1994). Complications of urinary tract infections associated with devices for long-term bladder management. J Hosp Infect 28, 177-194.

Stickler, D. J., Ganderton, L., King, J., Nettleton, J. \& Winters, C. (1993). Proteus mirabilis biofilms and the encrustation of urethral catheters. Urol Res 21, 407-411.

Stickler, D. J., Morris, N. S., Moreno, M. C. \& Sabbuba, N. A. (1998). Studies on the formation of crystalline bacterial biofilms on urethral catheters. Eur J Clin Microbiol Infect Dis 17, 649-652.

Stickler, D. J., Morris, N. S. \& Winters, C. (1999). Simple physical model to study formation and physiology of biofilms on urethral catheters. Methods Enzymol 310, 494-501.

Stickler, D. J., Jones, G. L. \& Russell, A. D. (2003). Control of encrustation and blockage of Foley catheters. Lancet 361, 1435-1437.

Suller, M. T. E., Anthony, V. J., Mathur, S., Feneley, R. C. L. \& Stickler, D. J. (2005). Factors modulating the $\mathrm{pH}$ at which calcium and magnesium phosphates precipitate from human urine. Urol Res 33, 254-260.

Wang, Y. H., Grenabo, L., Hedelin, H. \& Pettersson, S. (1994). The effects of sodium citrate and oral potassium citrate on urease-induced crystallization. Br J Urol 74, 409-415. 